\title{
In-migration and Dilution of Community Social Capital
}

\author{
Julie L. Hotchkiss and Anil Rupasingha
}

\section{Working Paper 2018-5 \\ July 2018}

\begin{abstract}
Consistent with predictions from the literature, we find that higher levels of in-migration dilute multiple dimensions of a community's level of social capital. The analysis employs a 2SLS methodology to account for potential endogeneity of migration.
\end{abstract}

JEL classification: R23, D71, C36, C38

Key words: social capital, migration, decennial census, social capital community benchmark survey, nonpublic data, simultaneous equations, endogeneity, factor analysis

https://doi.org/10.29338/wp2018-05

Comments and suggestions from colleagues at the Federal Reserve Bank of Atlanta are appreciated. Research assistance from Kalee Burns, Augustine Denteh, and Tom Zichong Qu is also appreciated. Any opinions and conclusions expressed herein are those of the authors and should not be attributed to the U.S. Census Bureau, the Federal Reserve Bank of Atlanta or the Federal Reserve System, the U.S. Department of Agriculture, or the Economic Research Service. All results have been reviewed to ensure that no confidential information is disclosed. The authors have no relevant or material financial interests that relate to the research described in this paper. Any remaining errors are the authors' responsibility.

Please address questions regarding content to Julie L. Hotchkiss (contact author), Federal Reserve Bank of Atlanta and Georgia State University, Research Department, 1000 Peachtree Street NE, Atlanta, GA 30309-4470, 404-498-8198, julie.l.hotchkiss@atl.frb.org, or Anil Rupasingha, U.S. Department of Agriculture, Economic Research Service, 1400 Independence Avenue SW, Mail Stop 1800, Washington, DC 20024, 202-694-5227, anil.rupasingha@ers.usda.gov.

Federal Reserve Bank of Atlanta working papers, including revised versions, are available on the Atlanta Fed's website at www.frbatlanta.org. Click "Publications" and then "Working Papers." To receive e-mail notifications about new papers, use frbatlanta.org/forms/subscribe. 


\section{In-migration and Dilution of Community Social Capital}

\section{Introduction and Background}

The extensive literature on social capital demonstrates that it has many forms and perspectives. ${ }^{1}$ This diverse nature of social capital may have prompted Woolcock $(2001,7)$ to declare that it has "become all things to all people, ..." Lack of coherent definition of the concept has led to formulation of different interpretations but fortunately these interpretations have more in common than contradictions (Grootaert and van Bastelaer 2002). Putnam (1995b, 19) defines social capital as interactions among individuals through social networks that lead to norms of reciprocity and trustworthiness. Putnam $(2001,22-24)$ also discusses two dimensions of social capital: "bridging" networks and connections that bring different kinds of people together far and near and "bonding" as networks that bring similar kinds of people together mostly locally. Coleman $(1988,598)$ defines social capital as "a variety of different entities, with two elements in common: they all consist of some aspect of social structure, and they facilitate certain actions of actors - whether personal or corporate actors - within the structure." Knack and Keefer (1997), while they do not provide an exact definition, use measures of trust at the country level in explaining economic growth. Woolcock (2001) describes social capital as norms and networks that facilitate collective action in the society. Portes $(1998,6)$, sounding a collective sentiment of the above papers, defines social capital as "... the ability of actors to secure benefits by virtue of membership in social networks or other social structures." Rather than offering another interpretation, following the above literature, we focus on social networks and interpersonal trust that facilitate collective action as social capital.

${ }^{1}$ See Durlauf (2002a) for a discussion of origins of the term social capital. 
It is widely believed that high levels of social capital within a community can be thought of as a local public good that generates positive externalities for members of the community. ${ }^{2}$ The many dimensions of social capital can produce benefits, for example, through higher levels of trust (reducing transaction costs), more extensive social networks (improving efficiency of the labor market, among other things), increased civic participation (resulting in more representative governance), increased productivity (improving a firm's competitive advantage), and greater participation in community organizations (strengthening goodwill), for example. ${ }^{3}$ It would stand to reason, then, as argued by Schiff (1992), that high levels of migration (i.e., the disruption of the social capital status quo) would dilute a community's level of social capital. ${ }^{4}$ Schiff (2002) also argues that countries' tolerance of, even preference for, movement of goods and services (i.e., trade liberalization) over their tolerance of movement of people (i.e., immigration) might be rooted in the role migration plays in the dilution of social capital, or, rather, dilution of customs and culture (also see Manole and Schiff 2013). Similarly, Antoci, Sacco, and Vanin (2007) argue that increased population heterogeneity reduces social participation (taking the view that social participation leads to social capital). Alesina and La Ferrara (2000) present evidence that more racially or ethnically heterogeneous communities have less social participation and those individuals who express views against racial mixing are less likely to participate in social

\footnotetext{
${ }^{2}$ While most social capital activities would lead to social interactions that may result in beneficial outcomes to wider society, there can be 'perverse' social capital as well (Rubio,1997) that may result in socially undesirable outcomes (such as activities by hate groups and gangs). ${ }^{3}$ Among many others, quantification of the positive contributions of social capital and its role in society can be found in Hanifan (1916); Knack and Keefer (1997); Boix and Posner (1998); Buonanno, Montolio, and Vanin (2009); Woolcock (2001); Biggart and Castanias (2001); and Florin, Lubatkin, and Schulze (2003).

${ }^{4}$ Hotchkiss and Rupasingha (2018) found that individuals are less likely to have migrated to communities with lower levels of social capital than their own, perhaps because they fear a dilution of their own personal social capital.
} 
activities the more racially fragmented their community is. Several other studies discuss how social capital is affected when people move from one location to another. Putnam (1995b, 669): "mobility, like frequent repotting of plants, tends to disrupt root systems, and it takes time for an uprooted individual to put down new roots." Coleman (1988) discusses how the performance of the children in school is affected every time a family moves. Several studies find that social capital depreciates when individuals leave their community (Putnam 1995a; DiPasquale and Glaeser 1999; Glaeser, Laibson, and Sacerdote 2002).

The purpose of this paper is to empirically test the notion that mobility and social capital are inversely related, and, specifically, whether greater in-migration dilutes a community's level of social capital. Controlling for potential endogeneity of migration in the determination of community-level social capital, we find that higher-levels of in-migration are associated with lower levels of social capital. If we have successfully accounted for the endogeneity, then we can interpret this relationship as causal. While the central hypothesis, based on above literature, is that social capital and migration are inversely related, due to multi-dimensional nature of the concept, some aspects of social capital may be affected positively by in-migration. For example, some forms of bridging social capital such as political activism and engagement by new migrants in an area may be enhanced by new migrants to that area. In this study, we investigate the impacts of in-migration on multiple dimensions of community social capital, some of which may be more likely to be negatively affected by in-migration than others.

There are many studies of determinants of community level social capital and a few of them address mobility or migration as a factor associated with social capital (for example see Glaeser 2001; Glaeser, Laibson, and Sacerdote 2002; Rupasingha, Goetz, and Freshwater 2006; Lesage and Ha 2012). However an area's migration rate is not typically included as a determinant 
except by Lesage and Ha (2012). Glaeser (2001) contends that individuals are less likely to invest in social capital when they move frequently. ${ }^{5}$ Glaeser, Laibson, and Sacerdote (2002) find a strong negative relationship between the probability of moving and membership in organizations. Rupasingha, Goetz, and Freshwater (2006) establish a strong positive relationship between the share of a community's long-term residents and production of social capital. Lesage and Ha (2012) find that while in-migration has a positive effect on county-level social capital, out-migration has a negative effect.

Another strand of literature studies the possibility that migrants may be attracted to places of higher social capital (for example see Kan 2007; David, Janiak, and Wasmer 2010; Alesina et al. 2015; Hotchkiss and Rupasingha 2018). Kan (2007) argues that interactions between friends and family members in the neighborhood are sources for help when in need and generate positive externalities such as low levels of crime and a better physical environment; these positive externalities discourage residents from moving. Such benefits can also be accrued by participating in neighborhood clubs (David, Janiak, and Wasmer 2010). David, Janiak, and Wasmer (2010) also use local social capital to explain the differences in geographic mobility between the North of Europe and the South of Europe and find evidence that social capital is negatively associated with geographic mobility. Alesina et al. (2015) show how moving costs will be high in societies that have stronger family ties and show empirical evidence to support this argument. Hotchkiss and Rupasingha (2018) study how individual relative to community social capital affects individual migration decisions and find that individuals are much less likely

\footnotetext{
${ }^{5}$ Analogously, Glaeser and Redlick (2009) find that communities with high levels of migrants will also invest less in social capital developments.
} 
to have moved to a community with average social capital levels lower than their own and that higher levels of community social capital act as positive pull-factor amenities.

This second strand of literature indicates that, in a more complete model of factors that include migration affecting social capital, migration would itself be endogenous and would be predicted to change as social capital changes. Therefore, any study that includes migration rate as a predictor in social capital should address this endogeneity issue. However, this is not the case of the studies discussed above. While controlling for potential endogeneity of migration in the determination of community-level social capital, we make use of several indices of social capital to incorporate the multi-dimensionality of the concept of social capital. Studies on social capital determination discussed above focus on associational densities and/or civic participation as the social capital measure. However, the wider literature suggests that social capital is not confined to these specific measures and establishes there are multiple dimensions of social capital. In this paper we incorporate several indices of social capital: religiosity, trust, political activism, political engagement, community involvement, and sociability.

Various measures related to these dimensions of social capital have been used in the literature of their impacts on social and economic outcomes. For example, several papers link social interactions related to religion to social and economic outcomes (see for example, Barro and McCleary 2003; Rupasingha and Chilton 2009; Guiso, Sapienza, and Zingales 2003). Trust in others or interpersonal trust have been used as measures of social capital in many papers, linking them to reducing transactions costs, enforcing contracts, and increasing government efficiency (see for example Fukuyama 1995; Knack and Keefer 1997; La Porta et al. 1997; Paxton 1999; and Capello and Lenzi 2014). Political activism and engagement has been linked to increasing government accountability (Knack, 2002) and federal spending (Levitt and 
Poterba,1999). The social capital field is overwhelmed with how social capital is enriched with increased community involvement or when people belong to voluntary groups and associations and participate in group and voluntary activities (see for example, Putnam et al. 1994; Knack 2002; and Narayan and Pritchett, 1999). Several studies use interactions between friends and family members in the neighborhood as measures of social capital (Kan 2007; David et al., 2010; Alesina et al. 2015; Tselios et al. 2015). Finally, Hotchkiss and Rupasingha (2018) study the effects of religiosity, trust, political activism, political engagement, community involvement, and sociability on migration.

Religiosity is measured using several indicators: church or synagogue membership, how often a respondent attended religious services, participation in church activities besides attending service, and participation in an organization affiliated with religion. Trust measures are derived from an individuals' responses to questions on whether most people can be trusted, whether they trust neighbors, how much they trust people in stores they shop, how much they trust people of other races, how much they trust local news media, how much they trust local community police, and the number of people each of them can confide in. Political activism includes activities such as signing a petition, attending a political rally or meeting, participating in demonstrations, boycotts, marches, participation in a political group, belonging to any group that took local action for reform, and participation in an ethnic, nationality, or civil rights organization. Political engagement includes activities such as whether the respondent read a daily newspaper, registered to vote, and whether he/she voted in the last presidential election. Community involvement includes measures such as participation in associations, groups, and volunteering activities. More specifically these activities include an individual's participation in a parent-teacher association or other school support group, neighborhood association, social or welfare organization, service or 
fraternal organization, and how often an individual attended a public meeting that discussed school, volunteered, or worked on a community project. And, lastly, sociability includes local social activities such as interactions with friends and neighbors and participation in local sports, arts, and other fun activities. More specifically the measures of sociability include individuals' participation in a sports club, league, or outdoor activity, how often they had friends over to their homes, how often they hung out with friends in a public place, how often they attended a parade, local sports or arts event, how often they played cards or board games with others, how often they took part in an artistic activity with a group, and number of close friends.

\section{Methodology and Data}

We make use of the 2000 U.S. Decennial Census (DC) which contains a question about whether or not individuals lived in the same house 5 years ago; if the answer is "no," we consider the individual as a "recent" in-migrant. We aggregate to the census tract level to obtain an area's rate of recent in-migration (the share of the current population that has moved to the census tract within the past five years). We use data from the year 2000 since that is the year for which we have measures of individual social capital activity from the Social Capital Community Benchmark Survey (SCCBS). The SCCBS is a survey that was conducted by the Saguaro Seminar at Harvard's Kennedy School of Government and disseminated by the University of Connecticut Roper Center for Public Opinion Archives. The SCCBS data contain 28,648 respondents across 5,187 census tracts, 3,017 of which have at least two respondents. We make use of the restricted version of the SCCBS in which census tracts are identified. Since measures of social capital are not contained in the DC, we use the SCCBS to estimate parameters for variables determining social capital that we then apply to observations in the DC. 
There are many candidates in the SCCBS to use as measures of social capital; for example, the survey contains sets of question responses to measure a person's civic participation, social trust, racial group trust, diversity of friendship network, group involvements (with and without church participation), faith-based social capital, organized group interactions, and informal social interactions. We estimate each person's probability of having a low, medium, and high level of six measures of social capital. We then aggregate these probabilities to the census tract level.

This process of using a secondary data set (the SCCBS) to estimate a non-existent variable (social capital) for use in a primary data set (the DC) is often referred to as two-sample two-stage least squares (Ridder and Moffitt 2007) and is described in detail in Appendix A. The end result is that we end up with a measure of both migration and social capital for observations in the DC that we can then aggregate to the census tract level. With these measures of recent inmigration and social capital we specify the relationship between mobility and social capital at the census tract level.

$S K_{c}=\alpha_{0}+\alpha_{1} M 5_{c}+\alpha_{2} S K_{n c}+\alpha_{3}^{\prime} X_{c}+\alpha_{4} A M_{c t y}+u_{i}$,

where, $M 5_{c}$ is a measure of recent in-migration in census tract $c$. It is the share of individuals in the census tract who indicated they had lived in their home for less than 5 years. $S K_{c}$ is a measure of social capital in census tract $c ; A M_{c t y}$ are county level amenities; $X_{c}$ are average demographic characteristics and other controls (such as state fixed-effects) in census tract $c$; and, finally, $S K_{n c}$ is a measure of the distance-weighted average SK in surrounding census tracts, which is included to be able to isolate the effect of migration specifically on a narrowly identified census tract, independent of the area's overall social capital environment. 
There is a significant amount of literature suggesting that recent migration is potentially endogenous to the determination of social capital -- either because in-migration is correlated with unobservables in the model, or because a community's level of social capital may act as an amenity directly increasing an area's in-migration (for example, see Hotchkiss and Rupasingha 2018). We expect the near-census tract social capital $\left(S K_{n c}\right)$ to remove some of this potential endogeneity from the error term, but in addition, we apply a two-stage least squares (2SLS) estimating strategy to instrument for recent in-migration at the census track level, as follows: $M 5_{c}=\theta_{0}+\theta_{1} S K_{c}+\theta_{2} M 5_{n c}+\theta_{3}^{\prime} X_{c}+\theta_{4} A M_{c t y}+\theta_{5}^{\prime} E C_{c}+\varepsilon_{i}$.

Recent in-migration is specified as a function of the community's level of social capital and the same community demographics and amenities defined for equation (1). In addition, recent inmigration to surrounding census tracts, $M 5_{n c}$, and economic conditions in the census tract, $E_{c}$ are included as unique regressors in the migration equation for identification purposes. Similar to the argument for including $S K_{n c}$ above, $M 5_{n c}$ is included in the migration equation in order to remove from the error term potential correlation of factors affecting migration patterns around the census tract from characteristics of the census tract itself.

The first-stage involves estimating the reduced-form version of equation (2), which includes all variables from equation (2) and equation (1), to obtain a predicted value for inmigration, which is then included in the second-stage estimation of the social capital equation:

$S K_{c}=\alpha_{0}+\alpha_{1} \widehat{M 5}_{c}+\alpha_{2} S K_{n c}+\alpha_{3}^{\prime} X_{c}+\alpha_{4} A M_{c t y}+u_{i}$.

Standard errors are clustered at the county level. This procedure is repeated six times for each social capital category (religiosity, trust, political activism, political engagement, community involvement, and sociability). 
In order to account for both the high and low probability levels of each social capital measure in the census tract, we construct what is referred to as the relative risk ratio. We use the $\log$ of this ratio, which is approximately normally distributed of social capital in the census tract: ${ }^{6}$

$S K_{c}=\log \left[\frac{\operatorname{Prob}(S K=H i g h}{\operatorname{Prob}(S K=\text { Low })}\right]$.

This ratio indicates the risk that a census tract has a high level of social capital relative to the risk of having a low level of social capital. ${ }^{7}$ Consider the case of two census tracts that both have probabilities of high social capital of 0.6 . The probability of low social capital for the first census tract is 0.1 and the probability of low social capital for the second census tract 0.4 . If we just modeled the probability a census tract has high social capital both of these tracts would look the same when in reality they are actually quite different. This social capital measure is continuous and falls between negative infinity and positive infinity.

The migration dependent variable in the first-stage estimation is the proportion of people in a census tract who have lived in their home less than a 5 years. It is a continuous measure and bounded by zero and one. Using a log transformation of the migration proportion yielded very similar results, so we retain the linear probability construction for simplicity.

For measures of amenities, we utilize the US Department of Agriculture's Natural Amenities Scale (see USDA n.d.). This county-level scale "is a measure of the physical characteristics of a county area that enhance the location as a place to live." This scale is created taking into account a county's average January temperature, average number of sunny January

\footnotetext{
${ }^{6}$ See (http://sphweb.bumc.bu.edu/otlt/MPHModules/BS/BS704_Confidence_Intervals/BS704_Confidence_Intervals8.html), as the measure. ${ }^{7}$ A clear explanation of the construction of a risk ratio and how it differs from an odds ratio can be found in (Schnell 2016). Also see "Risk Ratios and Rate Ratios (Relative Risk)" (n.d.)
} 
days, average low winter/summer temperature gap, low average July humidity, topical variation, and water area as a proportion of the total county area.

Finally, the full set of average census tract characteristics included as controls can be found in any of the tables in Appendix B, which contains the full set of second-stage parameter estimates. The key regressor of focus to test the hypothesis that greater in-migration dilutes a community's social capital is $\alpha_{1}$ in equation ( $\left.1^{\prime}\right)$. Theoretically, dilution of social capital would predict a negative sign for this parameter.

Table 1 contains the sample means for the full sample from the 2000 Decennial Census and for census tracts only in MSAs and in non-MSAs. Roughly 80 percent of census tracts are located in MSAs. In-migration is higher into MSA census tracts, and except for political activism, political engagement, and community involvement, non-MSA census tracts have higher levels of social capital. In other words, social capital related to religiosity, trust, and sociability is higher in rural locations. This may be due to the fact that people in rural locations are more family oriented and homogeneous in terms of ethnicity, race, and religion. More ethnically homogeneous communities tend to have higher social capital related to local social ties such as family and friends (Alesina and Giuliano 2010) and trust (Zak and Knack 2001). Census tracts in MSAs, relative to those in non-MSAs, have higher average education levels, more racial diversity, more single and younger residents, more amenities, higher unemployment, and higher incomes.

[Table 1 about here]

\section{Results}

Since we have six measures of social capital (religiosity, trust, political activism, political engagement, community involvement, and sociability), we have six sets of estimation results for 
the social capital equation (1') reported in Tables B1-B6 in Appendix B. Each table reports results for the full sample, then census tracts in MSAs and non-MSA's, separately. Results from the first-stage estimation of the reduced form of equation (2) are not presented. Importantly, however, the identifying regressors $\left(M 5_{n c}\right.$ and $\left.E C_{c}\right)$ are jointly statistically significantly different from zero for all sets of estimations. All estimations include state fixed effects (not reported) and the standard errors are clustered at the county level.

The results in Appendix B are generally consistent with the existing literature regarding important determinants of community social capital (Alesina and La Ferrara 2000; Glaeser, Laibson, and Sacerdote 2002; Rupasingha, Goetz, and Freshwater 2006). Generally, census tracts with higher levels education and citizens register higher levels of all social capital characteristics. Census tracts with higher levels of amenities had higher levels of social capital except on religiosity in the full sample and MSA only sample, and on political engagement for the nonMSA sample. Conceivably natural amenities may have a positive effect on some dimensions of social capital as some amenity sites such as local water bodies and mountains can foster both bonding and bridging social capital. ${ }^{8}$ The rest of the demographics are related to the area's social capital levels in varying degrees, depending on the social capital characteristic. Table 2 reports the coefficients of interest for the question of the impact of in-migration on the census tract average level of each social capital measure. Without exception, each measure of social capital is negatively affected by higher levels of in-migration, which is consistent with Schiff's (1992) hypothesis that higher levels of in-migration would dilute a community's level of social capital.

[Table 2 about here] ${ }^{8}$ Besser and Miller (2013) find that social capital is positively related to most amenities including
outdoor amenities. 
Translating the parameter coefficients into marginal effects is a bit tricky. Recall that the measure of each census tract's social capital used in the regression — trust, for example — is the $\log$ of the ratio of the average probability that residents in that census tract have a high level of trust to the average probability that residents have a low level of trust. ${ }^{9}$ This ratio is commonly referred to as a risk ratio. Referring to the sample means in Table 1, and continuing to use trust as the example, census tracts, on average are at roughly one times the risk of having a high probability of trust versus low probability of trust. ${ }^{10}$ Non-MSA census tracts have a higher "risk" for trust than MSA census tracts. We use the log of the risk ratio since the log is normally distributed and has a range of negative and positive infinity. However, this complicates the calculation of the marginal effect.

The coefficient on the migration regressor in the log risk-ratio equation for trust is -0.4461 . The marginal effect of a one unit increase in migration on the trust risk ratio (not the $\log$ risk ratio) is $-0.39[-0.4461 * \exp (-0.4461 * 0.27)$, where 0.27 is the average in-migration for the full sample]. This means that a one unit $(100 \%)$ increase in migration results in a decrease of 0.4 times the risk of the CT having high vs. low probability of trust. Dividing by 100 , then, means that a one percentage point increase in migration results in a decrease of relative risk of having a high probability of trust, on average, by 0.004 , which is about a $0.4 \%$ decrease in the average trust risk ratio for the full sample (0.004 divided by the average full-sample risk ratio of 1.072). In-migration has the largest negative impact on political activism. Using the same calculation strategy, a one percentage point increase in in-migration results in an average $2.4 \%$

\footnotetext{
${ }^{9}$ A census tract's average probability of having a high level of trust is the average of each resident's probability of having a high level of trust.

${ }^{10}$ By comparison, on average, census tracts are about four tenths the risk of having a high probability of political engagement relative to a low probability of political engagement.
} 
decrease in the average census tract political activism risk ratio for the full sample.

Table 2 presents results from estimating equation (1') separately for census tracts in MSAs and not in MSAs. As was mentioned earlier, and has been identified in the literature, nonMSA areas are more insular and community focused (Alesina and La Ferrara 2000; Rupasingha, Goetz, and Freshwater 2006). We might expect that new entrants into these communities would create greater disruption and, thus, have a greater dilution effect than into MSA communities. We see from the tables that this is the case for religiosity, trust, and community involvement. In contrast, the social capital characteristics of political activism, political engagement, and sociability (marginally) are diluted more in census tracts in MSAs than in non-MSAs as migration increases.

\section{Conclusion}

The analysis in this paper finds that higher levels of in-migration lead to lower levels of community social capital. While the research does not identify a mechanism for this relationship, others have suggested several sources. In-migration may increase a community's demographic heterogeneity, which Alesina and La Ferrara (2000) have found to diminish the community's level of social capital. Additionally, communities with high migration rates may not bother to invest in social capital development (e.g., see Glaeser and Redlick 2009). And, since migrants are less likely to have close family ties in their new communities, high levels of in-migration may very well undermine feelings of trust (Kan 2007). While our findings are more in line with the studies cited here, they contradict findings by Lesage and Ha (2012) in which they report that in-migration has a positive effect on county-level social capital. This contradictory finding may be due to various reasons including differences in social capital measures, the size of geographic 
units (tracts vs. county), estimation methods, and use of contemporaneous vs lag explanatory variables.

Regardless of the mechanism, this paper also offers an additional explanation for communities', sometimes hostile, objection to immigration (Schiff 2002; Manole and Schiff 2013). Opposition to immigration can be shown to be rooted in economic competition, cultural prejudice, and redistributive financial pressures (Baerg, Hotchkiss, and Quispe-Agnoli 2018). The results in this paper confirm that loss in community social capital may be yet another source of opposition to immigration. 


\section{References}

Alesina, Alberto, Pierre Cahuc, Yann Algan, and Paola Giuliano. 2015. "Family Values and the Regulation of Labor." Journal of the European Economic Association 13 (4): 599-630. https://doi.org/10.1111/\%28ISSN\%291542-4774/issues.

Alesina, Alberto, and Paola Giuliano. 2010. "The Power of the Family." Journal of Economic Growth 15 (2): 93-125. https://doi.org/10.1007/s10887-010-9052-z.

Alesina, Alberto, and Eliana La Ferrara. 2000. "Participation in Heterogeneous Communities." Quarterly Journal of Economics 115 (3): 847-904.

Angrist, Joshua D., and Alan B. Krueger. 1992. "The Effect of Age at School Entry on Educational Attainment: An Application of Instrumental Variables with Moments from Two Samples." Journal of the American Statistical Association 87 (418): 328-36. https://doi.org/10.2307/2290263. . 1995. "Split-Sample Instrumental Variables Estimates of the Return to Schooling." Journal of Business \& Economic Statistics 13 (2): 225-35. https://doi.org/10.2307/1392377.

Antoci, Angelo, Pier Luigi Sacco, and Paolo Vanin. 2007. "Social Capital Accumulation and the Evolution of Social Participation." The Journal of Socio-Economics, Essays on Behavioral Economics, 36 (1): 128-43. https://doi.org/10.1016/j.socec.2005.11.011.

Asquith, Brian J., Judith K. Hellerstein, Mark J. Kutzbach, and David Neumark. 2017. "Social Capital and Labor Market Networks." Working Paper 23959. National Bureau of Economic Research. https://doi.org/10.3386/w23959.

Baerg, Nicole Rae, Julie L. Hotchkiss, and Myriam Quispe-Agnoli. 2018. "Documenting the Unauthorized: Political Responses to Unauthorized Immigration.” Economics \& Politics 30 (1): 1-26. https://doi.org/10.1111/ecpo.12101.

Barro, Robert J., and Rachel M. McCleary. 2003. "Religion and Economic Growth across Countries." American Sociological Review 68 (5): 760-81. https://doi.org/10.2307/1519761.

Besser, Terry L., and Nancy J. Miller. 2013. "Social Capital, Local Businesses, and Amenities in U.S. Rural Prairie Communities.” Journal of Rural Studies 32: 186-95. https://doi.org/10.1016/j.jrurstud.2013.06.004.

Biggart, Nicole Woolsey, and Richard P. Castanias. 2001. "Collateralized Social Relations: The Social in Economic Calculation." American Journal of Economics and Sociology 60 (2): 471-500. https://doi.org/10.1111/1536-7150.00071.

Boix, Carles, and Daniel N. Posner. 1998. "Social Capital: Explaining Its Origins and Effects on Government Performance." British Journal of Political Science 28 (4): 686-93.

Buonanno, Paolo, Daniel Montolio, and Paolo Vanin. 2009. "Does Social Capital Reduce Crime?" The Journal of Law and Economics 52 (1): 145-70. https://doi.org/10.1086/595698.

Capello, Roberta, and Camilla Lenzi. 2014. "Spatial Heterogeneity in Knowledge, Innovation, and Economic Growth Nexus: Conceptual Reflections and Empirical Evidence." Journal of Regional Science 54 (2): 186-214. https://doi.org/10.1111/jors. 12074.

Carroll, Christopher D., Karen E. Dynan, and Spencer D. Krane. 2003. "Unemployment Risk and Precautionary Wealth: Evidence from Households' Balance Sheets." The Review of Economics and Statistics 85 (3): 586-604.

Coleman, James S. 1988. "Social Capital in the Creation of Human Capital." American Journal of Sociology 94: S95-120. 
Currie, Janet, and Aaron Yelowitz. 2000. “Are Public Housing Projects Good for Kids?” Journal of Public Economics 75 (1): 99-124. https://doi.org/10.1016/S0047-2727(99)00065-1.

David, Quentin, Alexandre Janiak, and Etienne Wasmer. 2010. "Local Social Capital and Geographical Mobility.” Journal of Urban Economics 68 (2): 191-204. https://doi.org/10.1016/j.jue.2010.04.003.

Dee, Thomas S., and William N. Evans. 2003. "Teen Drinking and Educational Attainment: Evidence from Two-Sample Instrumental Variables Estimates." Journal of Labor Economics 21 (1): 178-209. https://doi.org/10.1086/344127.

DiNardo, John, Nicole M. Fortin, and Thomas Lemieux. 1996. "Labor Market Institutions and the Distribution of Wages, 1973-1992: A Semiparametric Approach." Econometrica 64 (5): 1001-44. https://doi.org/10.2307/2171954.

DiPasquale, Denise, and Edward L. Glaeser. 1999. "Incentives and Social Capital: Are Homeowners Better Citizens?” Journal of Urban Economics 45 (2): 354-84. https://doi.org/10.1006/juec.1998.2098.

Durlauf, Steven N. 2002. "Bowling Alone: A Review Essay." Journal of Economic Behavior \& Organization 47 (3): 259-73. https://doi.org/10.1016/S0167-2681(01)00210-4.

Fang, Hanming, Michael P. Keane, and Dan Silverman. 2008. "Sources of Advantageous Selection: Evidence from the Medigap Insurance Market." Journal of Political Economy 116 (2): 303-3502-303.

Florin, Juan, Michael Lubatkin, and William Schulze. 2003. "A Social Capital Model of HighGrowth Ventures.” The Academy of Management Journal 46 (3): 374-84. https://doi.org/10.2307/30040630.

Fukuyama, Francis. 1995. Trust: The Social Virtues and the Creation of Prosperity. New York: Free Press.

Glaeser, Edward L. 2001. "The Formation of Social Capital.” Canadian Journal of Policy Research 2 (January): 34-40.

Glaeser, Edward L., David Laibson, and Bruce Sacerdote. 2002. "An Economic Approach to Social Capital.” The Economic Journal 112 (483): F437-58.

Glaeser, Edward L., and Charles Redlick. 2009. "Social Capital and Urban Growth." International Regional Science Review 32 (3): 264-99. https://doi.org/10.1177/0160017609336079.

Grootaert, Christiaan, and Thierry van Bastelaer, eds. 2002. Understanding and Measuring Social Capital: A Multi-Disciplinary Tool for Practitioners. Washington, D.C: World Bank Publications.

Guiso, Luigi, Paola Sapienza, and Luigi Zingales. 2003. "People's Opium? Religion and Economic Attitudes." Journal of Monetary Economics 50 (1): 225-82. https://doi.org/10.1016/S0304-3932(02)00202-7.

Hanifan, L. J. 1916. "The Rural School Community Center." The Annals of the American Academy of Political and Social Science 67: 130-38.

Hotchkiss, Julie L., and Anil Rupasingha. 2018. "Individual Social Capital and Migration." Working Paper 2018-3. Atlanta, GA: Federal Research Bank of Atlanta. https://www.frbatlanta.org:443/research/publications/wp/2018/03-individual-socialcapital-and-migration-2018-03-16.

Inoue, Atsushi, and Gary Solon. 2010. "Two-Sample Instrumental Variables Estimators." Review of Economics and Statistics 92 (3): 557-61. https://doi.org/10.1162/REST_a_00011. 
Kan, Kamhon. 2007. "Residential Mobility and Social Capital." Journal of Urban Economics 61 (3): 436-57. https://doi.org/10.1016/j.jue.2006.07.005.

Keane, Michael P, and Olena Stavrunova. 2014. "Adverse Selection, Moral Hazard and the Demand for Medigap Insurance.” Economics Papers from Economics Group, Nuffield College, University of Oxford No. 2014-W02. http://scor.com/en/sgrc/economyfinance/low-rates-environment/item/3174/3174.html?lout=sgrc.

Knack, Stephen. 2002. "Social Capital and the Quality of Government: Evidence from the States." American Journal of Political Science 46 (4): 772-85. https://doi.org/10.2307/3088433.

Knack, Stephen, and Philip Keefer. 1997. "Does Social Capital Have an Economic Payoff? A Cross-Country Investigation.” The Quarterly Journal of Economics 112 (4): 1251-88.

La Porta, Rafael, Florencio Lopez-de-Silanes, Andrei Shleifer, and Robert W. Vishny. 1997. "Trust in Large Organizations." The American Economic Review 87 (2): 333-38.

Lee, Young, and Roger H. Gordon. 2005. "Tax Structure and Economic Growth.” Journal of Public Economics 89 (5-6): 1027-43. https://doi.org/10.1016/j.jpubeco.2004.07.002.

Lesage, James P., and Christina L. Ha. 2012. "The Impact of Migration on Social Capital: Do Migrants Take Their Bowling Balls with Them?" Growth and Change 43 (1): 1-26. https://doi.org/10.1111/j.1468-2257.2011.00575.x.

Levitt, Steven D., and James M. Poterba. 1999. "Congressional Distributive Politics and State Economic Performance." Public Choice 99 (1/2): 185-216.

Manole, Vlad, and Maurice Schiff. 2013. "Migration and Diversity: Human versus Social Capital." Review of International Economics 21 (2): 281-94. https://doi.org/10.1111/roie.12036.

Narayan, Deepa, and Lant Pritchett. 1999. "Cents and Sociability: Household Income and Social Capital in Rural Tanzania." Economic Development and Cultural Change 47 (4): 871-97. https://doi.org/10.1086/452436.

Paxton, Pamela. 1999. "Is Social Capital Declining in the United States? A Multiple Indicator Assessment.” American Journal of Sociology 105 (1): 88-127. https://doi.org/10.1086/210268.

Portes, Alejandro. 1998. "Social Capital: Its Origins and Applications in Modern Sociology." Annual Review of Sociology; Palo Alto 24: $0 \_12$.

Putnam, Robert D. 1995a. "Tuning In, Tuning Out: The Strange Disappearance of Social Capital in America." PS: Political Science and Politics 28 (4): 664-83. https://doi.org/10.2307/420517.

_ 1995b. "Bowling Alone: America's Declining Social Capital." Journal of Democracy 6 (1): 65-78. https://doi.org/10.1353/jod.1995.0002.

2001. Bowling Alone: The Collapse and Revival of American Community. 1 st edition. New York, NY: Touchstone Books by Simon \& Schuster.

Putnam, Robert D., Robert Leonardi, and Raffaella Y. Nanetti. 1994. Making Democracy Work: Civic Traditions in Modern Italy. Princeton University Press.

Ridder, Geert, and Robert Moffitt. 2007. "Chapter 75 The Econometrics of Data Combination." In Handbook of Econometrics, edited by James J. Heckman and Edward E. Leamer, 6, Part B:5469-5547. Elsevier. http://www.sciencedirect.com/science/article/pii/S1573441207060758. 
“Risk Ratios and Rate Ratios (Relative Risk).” n.d. Accessed February 16, 2018. http://sphweb.bumc.bu.edu/otlt/MPHModules/EP/EP713_Association/EP713_Association3.html.

Rubio, Mauricio. 1997. "Perverse Social Capital--Some Evidence from Colombia." Journal of Economic Issues 31 (3): 805-16.

Rupasingha, Anil, and John b. Chilton. 2009. "Religious Adherence and County Economic Growth in the US." Journal of Economic Behavior \& Organization 72 (1): 438-50. https://doi.org/10.1016/j.jebo.2009.05.020.

Rupasingha, Anil, Stephan J. Goetz, and David Freshwater. 2006. "The Production of Social Capital in US Counties." The Journal of Socio-Economics, Essays on Behavioral Economics, 35 (1): 83-101. https://doi.org/10.1016/j.socec.2005.11.001.

Schiff, Maurice. 1992. "Social Capital, Labor Mobility, and Welfare: The Impact of Uniting States." Rationality and Society 4 (2): 157-75. https://doi.org/10.1177/1043463192004002003.

—. 2002. "Love Thy Neighbor: Trade, Migration, and Social Capital." European Journal of Political Economy 18 (1): 87-107. https://doi.org/10.1016/S0176-2680(01)00070-2.

Schnell, Audrey. 2016. "The Difference Between Relative Risk and Odds Ratios." 2016. https://www.theanalysisfactor.com/the-difference-between-relative-risk-and-odds-ratios/.

Tselios, Vassilis, Inge Noback, Jouke van Dijk, and Philip McCann. 2015. "Integration of Immigrants, Bridging Social Capital, Ethnicity, and Locality." Journal of Regional Science 55 (3): 416-41. https://doi.org/10.1111/jors. 12160.

USDA. n.d. "USDA ERS - Natural Amenities Scale.” Accessed February 16, 2018. https://www.ers.usda.gov/data-products/natural-amenities-scale.aspx.

Woolcock, Michael. 2001. "The Place of Social Capital in Understanding Social and Economic Outcomes." Canadian Journal of Policy Research 2 (1): 11-17.

Zak, Paul J., and Stephen Knack. 2001. "Trust and Growth." The Economic Journal 111 (470): 295-321. https://doi.org/10.1111/1468-0297.00609. 
Table 1. Census tract level means for 2000 Decennial Census.

\begin{tabular}{|c|c|c|c|}
\hline Variable & Full-sample & $\begin{array}{c}\text { MSA } \\
\text { Sample }\end{array}$ & $\begin{array}{c}\text { non-MSA } \\
\text { Sample }\end{array}$ \\
\hline \multirow[t]{2}{*}{ Recent In-Migration } & 0.2744 & 0.2863 & 0.2303 \\
\hline & $(0.1392)$ & $(0.1459)$ & $(0.0994)$ \\
\hline \multirow[t]{2}{*}{ Religiosity risk ratio } & 1.249 & 1.225 & 1.338 \\
\hline & $(0.6259)$ & $(0.6097)$ & $(0.6752)$ \\
\hline \multirow[t]{2}{*}{ Trust risk ratio } & 1.072 & .96 & 1.484 \\
\hline & $(0.7896)$ & $(0.7227)$ & $(0.8836)$ \\
\hline \multirow[t]{2}{*}{ Political Activism risk ratio } & 0.4016 & 0.4355 & 0.2764 \\
\hline & $(0.3541)$ & $(0.3854)$ & $(0.1425)$ \\
\hline \multirow[t]{2}{*}{ Political Engagement risk ratio } & 0.9834 & 1.016 & 0.8618 \\
\hline & $(0.7018)$ & $(0.7528)$ & $(0.4472)$ \\
\hline \multirow[t]{2}{*}{ Community Involvement risk ratio } & 0.9225 & 0.9666 & 0.76 \\
\hline & $(0.6622)$ & $(0.7275)$ & $(0.2653)$ \\
\hline \multirow[t]{2}{*}{ Sociability risk ratio } & 0.9368 & 0.8919 & 1.102 \\
\hline & $(0.3638)$ & $(0.3575)$ & $(0.338)$ \\
\hline \multirow[t]{2}{*}{ Census tract is in a $\mathrm{MSA}=0,1$} & 0.7867 & -- & -- \\
\hline & $(0.4096)$ & & \\
\hline \multirow[t]{2}{*}{ Share of CT HS only } & 0.2934 & 0.2752 & 0.3605 \\
\hline & $(0.1025)$ & $(0.1002)$ & $(0.0809)$ \\
\hline \multirow[t]{2}{*}{ Share of CT SCOLL only } & 0.2805 & 0.2841 & 0.2675 \\
\hline & $(0.0809)$ & $(0.0822)$ & $(0.0746)$ \\
\hline \multirow[t]{2}{*}{ Share of CT COLL degree } & 0.218 & 0.2386 & 0.1421 \\
\hline & $(0.1641)$ & $(0.1738)$ & $(0.0866)$ \\
\hline \multirow[t]{2}{*}{ Share of CT Hispanic } & 0.1041 & 0.1201 & 0.0452 \\
\hline & $(0.1803)$ & $(0.1914)$ & $(0.1134)$ \\
\hline \multirow[t]{2}{*}{ Share of CT black non-Hispanic } & 0.1264 & 0.1412 & 0.072 \\
\hline & $(0.2322)$ & $(0.2468)$ & $(0.1561)$ \\
\hline \multirow[t]{2}{*}{ Share of CT other race non-Hispanic } & 0.0567 & 0.0631 & 0.033 \\
\hline & $(0.0897)$ & $(0.0878)$ & $(0.0929)$ \\
\hline \multirow[t]{2}{*}{ Average age of CT residents } & 45.27 & 44.80 & 47.01 \\
\hline & $(4.581)$ & $(4.731)$ & $(3.464)$ \\
\hline \multirow[t]{2}{*}{ Share of CT residents who are married } & 0.5813 & 0.563 & 0.6489 \\
\hline & $(0.1455)$ & $(0.1509)$ & $(0.0972)$ \\
\hline Share of CT residents who are citizens & 0.9278 & 0.9139 & 0.9792 \\
\hline
\end{tabular}




\begin{tabular}{lccc}
\hline Variable & Full-sample & $\begin{array}{c}\text { MSA } \\
\text { Sample }\end{array}$ & $\begin{array}{c}\text { non-MSA } \\
\text { Sample }\end{array}$ \\
\hline & & $(0.1184)$ & $(0.0424)$ \\
Average county-level amenities scale & 1.138 & 1.427 & .0715 \\
& $(3.256)$ & $(3.407)$ & $(2.339)$ \\
CT unemployment rate $(16+)$ & 0.0206 & 0.021 & 0.0191 \\
Share of CT whose income is $\geq \$ 30 \mathrm{~K}$ & $(0.0149)$ & $(0.0155)$ & $(0.0119)$ \\
& 0.7315 & 0.7493 & 0.6657 \\
Number of Census Tracts & $(0.175)$ & $(0.1816)$ & $(0.1284)$ \\
\hline
\end{tabular}


Table 2. 2SLS parameter coefficients for the impact of in-migration on community social capital levels, full-sample, MSA, and non-MSA separately

\begin{tabular}{lccc}
\hline Social Capital Measure & Full-sample & MSA only & non-MSA only \\
\hline Religiosity & -0.1136 & -0.1175 & $-1.511^{* * *}$ \\
& $(0.1019)$ & $(0.0983)$ & $(0.1476)$ \\
Trust & $-0.4461^{* * *}$ & $-0.3626 * * *$ & $-1.876^{* * *}$ \\
& $(0.1281)$ & $(0.1337)$ & $(0.3017)$ \\
Political Activism & $-1.409 * * *$ & $-1.355^{* * *}$ & $-0.8066^{* * *}$ \\
& $(0.1553)$ & $(0.1631)$ & $(0.1718)$ \\
Political Engagement & $-0.9420 * * *$ & $-0.9442 * * *$ & $-0.7117 * * *$ \\
& $(0.0754)$ & $(0.0800)$ & $(0.1547)$ \\
Community Involvement & & & $-1.504 * * *$ \\
& $-1.043^{* * *}$ & $-0.9821 * * *$ & $(0.1945)$ \\
Sociability & $(0.1100)$ & $(0.1157)$ & $-0.5903 * * *$ \\
Obs. (\# of census tracts) & & & $(0.2164)$ \\
\hline Notes: Comp & $-0.6861 * * *$ & $-0.6486 * * *$ & 13,669
\end{tabular}

Notes: Complete 2SLS second-stage results can be found in Appendix B. Unit of analysis is the census tract; standard errors (in parentheses) are clustered at the county level. 


\section{Appendix A: Estimating Social Capital for Observations in the Decennial Census}

Before aggregating to the census tract level, we need to obtain estimates of individual levels of social capital for observations in the Decennial Census (DC). This appendix describes how we make use of the restricted Social Capital Community Benchmark Survey (SCCBS) from 2000 to identify determinants of individual levels of six dimensions of social capital. Those determinants are then used to predict social capital for observations in the non-public version of the DC. The commonly applied technique of using one sample to obtain predictors for an outcome to be applied to a second sample is called two-sample two-stage least squares (2S2SLS) (Ridder and Moffitt 2007), made popular by Angrist and Krueger $(1992,1995) .{ }^{11}$ The individual social capital estimates are then averaged to obtain social capital estimates at the census tract level.

In 2000 the Roper foundation conducted a national survey, the Social Capital Community Benchmark Survey (SCCBS), to gauge the level of a multitude of dimensions of individual social capital. A more recent 2006 SCCBS survey exists, however it does not contain an indicator for census tract, which is important for constructing an instrument for individual social capital (see https://ropercenter.cornell.edu/2006-social-capital-community-benchmark-survey/). We use the SCCBS as the source for estimating social capital determinants. Fortunately, the SCCBS and the DC are fairly harmonious with respect to their measures of demographics. This is fortunate, since we are restricted to those variables that are found in both surveys in order to use the estimated parameters from one data set to predict social capital in the second.

${ }^{11}$ Also see Inoue and Solon (2010) for the distinction between 2S2SLS and two-sample instrumental variables (2SIV). Other applications of 2S2SLS can be found in Dee and Evans 2003), Carroll, Dynan, and Krane (2003), Currie and Yelowitz (2000), Fang, Keane, and Silverman (2008), and Keane and Stavrunova (2014). 
A.1 Creating Weights to use in the SCCBS. Since we are predicting out of sample and in spite of the fact that both the DC and the SCCBS are both national surveys, we are interested in how the two samples compare in their distributions across demographics. In other words, we want to be sure that the parameter estimates obtained from the SCCBS sample are likely to be applicable, at least at the means, to observations in the DC. Both the SCCBS and DC surveys contain individual weights designed to generate a random national sample. Using just the DC provided weights, 96 percent of the weighted means of the common variables in the DC and SCCBS are statistically different from one another at least at the 95 percent confidence level.

To estimate the social capital equation on a sample that is more representative of the DC (for which the prediction will be made), we use an inverse probability weighting methodology, akin to the one used in DiNardo, Fortin, and Lemieux (1996), in order to create a counterfactual distribution of the SCCBS that is much more similar to the DC. This amounts to estimating, in the combined DC and SCCBS samples, the probability of an observation being observed in SCCBS, using as explanatory variables as many demographics and their cross-multiples as is feasible:

$$
P(\text { observation } i \in \operatorname{SCCBS} \mid X)=\Lambda\left(X^{\prime} b\right) \text {. }
$$

The parameter estimates from this logit model are then used to construct the inverse probability ratio, $\frac{\Lambda\left(X^{\prime} \hat{b}\right)}{1-\Lambda\left(X^{\prime} \hat{b}\right)}$, for each observation in the SCCBS. This is the re-weighting function used to modify the individual weight provided in the SCCBS.

There is significant improvement using the inverse-weighted adjustment to the means in the SCCBS. Using the constructed inverse probability weights, the percent of common variables that are statistically different from one another is reduced to 64 percent, with 85 percent of the re-weighted means of all variables being significantly closer to the DC mean than they were 
using the survey supplied weights (additional details of the means comparisons are suppressed for confidentiality reasons). ${ }^{12}$

A.2 Identifying a Person's Unobserved Social Capital. We make use of factor analysis to elicit the common factor from multiple questions related to a specific measure of social capital. This type of analysis uses the responses to those questions in the SCCBS in order to uncover a person's latent degree of social capital. From this analysis, we obtain a single value for each person for each type of social capital. The questions from the SCCBS that are combined, via factor analysis, to construct each social capital measure are contained in Table A1.

[Table A1 about here]

The factor, or latent measure, does not have an easy interpretation and are ordinal by construct. We, therefore, translate it into a categorical value. We specify three "levels" of social capital: high, medium, and low. We then estimate an ordered probit to determine the relationship between a person's observable characteristics and their level of each type of social capital. Creating three categories is, of course, arbitrary, but offers an easy interpretation for low, medium, and high values.

A.3 Estimating Social Capital. Since the categories of each social capital measure are ordered from lower to higher levels of the social capital variable in question, we estimate the parameters of each social capital equation as an ordered logit. The probability that individual $i$, living in census tract $c$, has social capital level $k$ of type $j$ ( $j=$ sociability, community involvement, trust, political activism, political engagement, and religiosity) is formally expressed as:

${ }^{12}$ A condition of accessing non-public data through the Federal Statistical Research Data Centers is that all output is subjected to disclosure review by the Census Bureau. The Census Bureau restricts the number of tables showing sample means that can be made public through this process. 


$$
\operatorname{Pr}\left[S K_{i}^{j}=k\right]=\operatorname{Pr}\left[\mu_{k-1}<\alpha_{0}+\mathrm{A}^{\prime} X_{i}+\mathrm{B}^{\prime} Z_{c}+u_{i} \leq \mu_{k}\right]
$$

where $u_{i t}$ is assumed to be logistically distributed and the estimated cutpoints $\mu=1,2$ separate three possible outcomes $k=$ low, medium, high for each type of social capital.

Regressors $X_{i}$ reflect person $i$ 's demographics and $Z_{c}$ are average census tract characteristics for each observation. The theory is that the characteristics of those in close proximity influence one's level of social capital. Potential key average characteristics are the share of employment near the person's census tract employed in "social" occupations and in social industries which include individuals employed as independent artists, performing arts, and spectator sports (NAICS 856); by bowling centers (858); by religious organizations (916); by civic, social, advocacy organizations and grantmaking services (917); by labor unions (918); and by business, professional, and political organizations (919) (see Asquith et al. 2017; Rupasingha, Goetz, and Freshwater 2006).

There is some concern, however, that characteristics in a person's census tract $\left(Z_{c}\right)$ may be endogenous to that person's level of social capital. In other words, there are unobservable factors both affecting a person's level of social activity and the location where that person has chosen to reside. This potential for endogeneity is why average demographic characteristics in surrounding census tracts $\left(Z_{n c}\right)$ will be used instead of the value of those variables in the person's own census tract $\left(Z_{c}\right)$, These surrounding characteristics will be inverse weighted by the distance (from centroids) of the census tract from that person's census tract. Census tracts in the person's own and surrounding states will be used to construct the average. This method of construction of an instrument in the face of potential geographic endogeneity has been widely applied in the empirical literature (for example, see Lee and Gordon 2005). 
The parameter estimates from the ordered logits are then used to predict the level of each type of social capital for respondents in the DC, which are then aggregated to the census tract level (predicted values for $S K_{c}$ and $S K_{n c}$ in equations 1 and 2). Results from this first stage analysis have not been disclosed in the interest of parsimony.

To apply the 2S2SLS methodology with some confidence (i.e., that our predicted social capital levels in the DC are believable), our first stage estimation should demonstrate a good fit of the data. While most studies using 2S2SLS spend very little time on this issue, we report the goodness of fit for each ordered logit analysis in Table A2.

[Table A2 about here]

We do well, generally, predicting low and high levels of each social capital measure, but not so well predicting a medium outcome. For example, in the SCCBS, nearly 68 percent of those with an actual medium level of political activism were predicted with a low level. However, the correlations reported at the bottom of the table, compare favorably with first-stage R-squared statistics reported by others who have employed this methodology. Dee and Evans (2003) make use of predictions from a first stage estimation with R-squared statistics less than 0.02; Carroll, Dynan, and Krane (2003) report first-stage adjusted R-squared test statistics between 0.28 and 0.48; Currie and Yelowitz (2000) report a first-stage R-squared statistic less than 0.1; Fang, Keane, and Silverman (2008) and Keane and Stavrunova (2014) contain similar analyses using the same data and fist-stage R-squared statistics ranging from 0.02 to 0.25 .

For each census tract, then, we calculate the share of individuals with high and low levels of each social capital measure from which we then construct something like an odds ratio that describes a census tract's probability of high, relative to low, levels of each social capital measure. 
Table A1. Questions used to construct each social capital measure via factor analysis.

\begin{tabular}{|c|c|}
\hline Variable from SCCBS & Description \\
\hline \multicolumn{2}{|c|}{ Community Involvement } \\
\hline GRPPTA & Participate in parent association or other school support \\
\hline GRPNEI & Participate in neighborhood association \\
\hline GRPSOC & Participate in social or welfare organization \\
\hline GRPFRAT & Participate in service or fraternal organization \\
\hline PUBMEET2 & How often attended a public meeting discussing school \\
\hline VOLTIME2 & Number of times volunteered \\
\hline PROJECT & Worked on community project in past 12 months \\
\hline \multicolumn{2}{|l|}{ Sociability } \\
\hline GRPSPORT & Participate in sports club, league, or outdoor activity \\
\hline FRNDHOM2 & How often had friends over to your home \\
\hline FRNDHNG2 & How often hung out with friends in a public place \\
\hline PARADE2 & How often attended parade, local sports or arts event \\
\hline CARDS2 & How often played cards or board games with others \\
\hline FRIENDS & Number of close friends \\
\hline ARTIST2 & How often took part in artistic activity with group \\
\hline \multicolumn{2}{|l|}{ Religiosity } \\
\hline RELMEM2 & Church or synagogue member \\
\hline RELATEN2 & How often attend religious service \\
\hline RELPART2 & Participate in church activities besides attending service \\
\hline GRPREL & Participate in organization affiliated with religion \\
\hline \multicolumn{2}{|l|}{ Trust } \\
\hline TRUST2 & Whether most people can be trusted \\
\hline TR2NEI & How much trust neighbors \\
\hline TR2SHOP & How much trust people in stores you shop \\
\hline RACETRST & How much trust people of other race \\
\hline TR2NEWS & How much trust local news media \\
\hline TR2COP & How much trust local community police \\
\hline CONFIDE & Number of people you can confide in \\
\hline \multicolumn{2}{|l|}{ Political Activism } \\
\hline PETITION & Signed a petition in past 12 months \\
\hline RALLY & Attended a political rally or meeting in past 12 months \\
\hline MARCH & Participated in demonstrations, boycotts, marches \\
\hline
\end{tabular}




\begin{tabular}{ll}
\hline Variable from SCCBS & Description \\
\hline GRPPOL & Participate in political group \\
REFORM & Belong to any group that took local action for reform \\
GRPETH & Participate in ethnic, nationality, or civil rights organization \\
Political Engagement & \\
PAPER & Days in past week respondent read a daily newspaper \\
REGVOTE & Currently registered to vote \\
VOTEUS & Voted in 1996 presidential election \\
\hline
\end{tabular}


Table A2. Actual and predicted categories of social capital measures (goodness-of-fit) within the SCCBS data set.

\begin{tabular}{|c|c|c|c|c|c|c|}
\hline VARIABLES & Religiosity & Trust & $\begin{array}{l}\text { Political } \\
\text { Activism }\end{array}$ & $\begin{array}{c}\text { Political } \\
\text { Engagement }\end{array}$ & $\begin{array}{l}\text { Community } \\
\text { Involvement }\end{array}$ & Sociability \\
\hline \multicolumn{7}{|l|}{ Actual Level of Low } \\
\hline Predicted level of Low & $45.21 \%$ & $60.36 \%$ & $85.22 \%$ & $61.55 \%$ & $54.76 \%$ & $59.96 \%$ \\
\hline Predicted level of Medium & $25.87 \%$ & $24.13 \%$ & $12.46 \%$ & $30.94 \%$ & $32.69 \%$ & $24.02 \%$ \\
\hline Predicted level of High & $28.91 \%$ & $15.51 \%$ & $2.32 \%$ & $7.51 \%$ & $12.55 \%$ & $16.02 \%$ \\
\hline \multicolumn{7}{|l|}{ Actual Level of Medium } \\
\hline Predicted level of Low & $29.72 \%$ & $29.52 \%$ & $67.93 \%$ & $16.21 \%$ & $32.39 \%$ & $42.01 \%$ \\
\hline Predicted level of Medium & $26.26 \%$ & $33.18 \%$ & $24.56 \%$ & $52.91 \%$ & $40.67 \%$ & $30.57 \%$ \\
\hline Predicted level of High & $44.02 \%$ & $37.30 \%$ & $7.51 \%$ & $30.88 \%$ & $26.94 \%$ & $27.42 \%$ \\
\hline \multicolumn{7}{|l|}{ Actual Level of High } \\
\hline Predicted level of Low & $14.24 \%$ & $14.25 \%$ & $55.63 \%$ & $6.86 \%$ & $15.55 \%$ & $26.61 \%$ \\
\hline Predicted level of Medium & $21.53 \%$ & $31.51 \%$ & $30.52 \%$ & $33.61 \%$ & $34.29 \%$ & $29.10 \%$ \\
\hline Predicted level of High & $64.24 \%$ & $54.25 \%$ & $13.85 \%$ & $59.54 \%$ & $50.15 \%$ & $44.29 \%$ \\
\hline $\begin{array}{l}\text { Correlations between actual } \\
\text { and predicted categories across } \\
\text { individuals }\end{array}$ & 0.31 & 0.41 & 0.28 & 0.56 & 0.39 & 0.30 \\
\hline
\end{tabular}




\section{Appendix B: Full Set of 2SLS Second-stage Parameter Estimates and Standard Errors for Social Capital Equations.}

Table B1. Religiosity

\begin{tabular}{|c|c|c|c|}
\hline Regressors: & $\begin{array}{c}\text { Full } \\
\text { sample }\end{array}$ & $\begin{array}{l}\text { MSA } \\
\text { only }\end{array}$ & $\begin{array}{c}\text { non-MSA } \\
\text { only }\end{array}$ \\
\hline \multirow[t]{2}{*}{ Recent In-Migration } & -0.1136 & -0.1175 & $-1.511 * * *$ \\
\hline & $(0.1019)$ & $(0.0983)$ & $(0.1476)$ \\
\hline \multirow[t]{2}{*}{ Near Census SK level } & $1.471 * * *$ & $1.473 * * *$ & $1.332 * * *$ \\
\hline & $(0.0422)$ & $(0.0454)$ & $(0.0467)$ \\
\hline \multirow[t]{2}{*}{ Amenities Scale } & $-0.0125 * * *$ & $-0.0153 * * *$ & 0.0004 \\
\hline & $(0.0025)$ & $(0.0033)$ & $(0.0018)$ \\
\hline \multirow[t]{2}{*}{ Share of CT HS only } & $0.1512 * * *$ & $0.1623 * * *$ & $0.5832 * * *$ \\
\hline & $(0.0407)$ & $(0.0453)$ & $(0.0483)$ \\
\hline \multirow[t]{2}{*}{ Share of CT SCOLL only } & $0.6002 * * *$ & $0.5362 * * *$ & $1.443 * * *$ \\
\hline & $(0.0557)$ & $(0.0535)$ & $(0.0736)$ \\
\hline \multirow[t]{2}{*}{ Share of CT COLL degree } & $0.5528 * * *$ & $0.5170 * * *$ & $1.609 * * *$ \\
\hline & $(0.0472)$ & $(0.0454)$ & $(0.0613)$ \\
\hline \multirow[t]{2}{*}{ Share of CT Hispanic } & $0.7056^{* * *}$ & $0.7136 * * *$ & $0.3929 * * *$ \\
\hline & $(0.0329)$ & $(0.0364)$ & $(0.0319)$ \\
\hline \multirow[t]{2}{*}{ Share of CT black non-Hispanic } & $0.8890 * * *$ & $0.8780 * * *$ & $0.9187 * * *$ \\
\hline & $(0.0203)$ & $(0.0210)$ & $(0.0242)$ \\
\hline \multirow[t]{2}{*}{ Share of CT oth. race non-Hisp } & $0.0833 * * *$ & $0.0983 * * *$ & -0.0099 \\
\hline & $(0.0290)$ & $(0.0376)$ & $(0.0304)$ \\
\hline \multirow[t]{2}{*}{ Average Age of CT residents } & $0.0344 * * *$ & $0.0407 * * *$ & $-0.0429 * * *$ \\
\hline & $(0.0065)$ & $(0.0067)$ & $(0.0101)$ \\
\hline \multirow[t]{2}{*}{ Average Age 2 of CT residents } & $-0.0002 * * *$ & $-0.0003 * * *$ & $0.0005 * * *$ \\
\hline & $(0.0001)$ & $(0.0001)$ & $(0.0001)$ \\
\hline \multirow[t]{2}{*}{ Share of CT who married } & $1.197 * * *$ & $1.228 * * *$ & $0.7240 * * *$ \\
\hline & $(0.0264)$ & $(0.0275)$ & $(0.0508)$ \\
\hline \multirow[t]{2}{*}{ Share of CT citizens } & $0.5397 * * *$ & $0.5691 * * *$ & $-0.4564 * * *$ \\
\hline & $(0.0545)$ & $(0.0569)$ & $(0.0998)$ \\
\hline \multirow[t]{2}{*}{$\mathrm{CT}$ is a $\mathrm{MSA}=0,1$} & $0.1001 * * *$ & & \\
\hline & $(0.0047)$ & & \\
\hline \multirow[t]{2}{*}{ Constant } & $-2.967 * * *$ & $-3.038 * * *$ & 0.1288 \\
\hline & $(0.2058)$ & $(0.2117)$ & $(0.2938)$ \\
\hline Obs. (number of census tracts) & 64,083 & 50,414 & 13,669 \\
\hline R-squared & 0.9332 & 0.9318 & 0.9493 \\
\hline
\end{tabular}

Notes: Standard errors are in parentheses and clustered at the county level. 
Table B2. Trust

\begin{tabular}{|c|c|c|c|}
\hline Regressors: & $\begin{array}{c}\text { Full } \\
\text { sample }\end{array}$ & $\begin{array}{l}\text { MSA } \\
\text { only }\end{array}$ & $\begin{array}{c}\text { non-MSA } \\
\text { only }\end{array}$ \\
\hline \multirow[t]{2}{*}{ Recent In-Migration } & $-0.4461 * * *$ & $-0.3626 * * *$ & $-1.876 * * *$ \\
\hline & $(0.1281)$ & $(0.1337)$ & $(0.3017)$ \\
\hline \multirow[t]{2}{*}{ Near Census SK level } & $1.123 * * *$ & $1.126^{* * *}$ & $0.8595 * * *$ \\
\hline & $(0.0376)$ & $(0.0395)$ & $(0.0533)$ \\
\hline \multirow[t]{2}{*}{ Amenities Scale } & $0.0097 *$ & $0.0147 * *$ & 0.0037 \\
\hline & $(0.0054)$ & $(0.0068)$ & $(0.0023)$ \\
\hline \multirow[t]{2}{*}{ Share of CT HS only } & $0.8589 * * *$ & $0.9183 * * *$ & $0.9032 * * *$ \\
\hline & $(0.0509)$ & $(0.0549)$ & $(0.0827)$ \\
\hline \multirow[t]{2}{*}{ Share of CT SCOLL only } & $1.249 * * *$ & $1.315^{* * *}$ & $1.575^{* * *}$ \\
\hline & $(0.0608)$ & $(0.0635)$ & $(0.1479)$ \\
\hline \multirow[t]{2}{*}{ Share of CT COLL degree } & $1.949 * * *$ & $1.966^{* * *}$ & $2.231 * * *$ \\
\hline & $(0.0549)$ & $(0.0560)$ & $(0.1169)$ \\
\hline \multirow[t]{2}{*}{ Share of CT Hispanic } & $-0.6768 * * *$ & $-0.6750 * * *$ & $-0.9316^{* * *}$ \\
\hline & $(0.0460)$ & $(0.0534)$ & $(0.0472)$ \\
\hline \multirow[t]{2}{*}{ Share of CT black non-Hispanic } & $-1.151 * * *$ & $-1.146 * * *$ & $-1.174 * * *$ \\
\hline & $(0.0235)$ & $(0.0247)$ & $(0.0276)$ \\
\hline \multirow[t]{2}{*}{ Share of CT oth. race non-Hisp } & $-0.4107 * * *$ & $-0.5007 * * *$ & $-0.4510 * * *$ \\
\hline & $(0.0414)$ & $(0.0609)$ & $(0.0317)$ \\
\hline \multirow[t]{2}{*}{ Average Age of CT residents } & $0.0407 * * *$ & $0.0455^{* * *}$ & -0.0148 \\
\hline & $(0.0084)$ & $(0.0093)$ & $(0.0148)$ \\
\hline \multirow[t]{2}{*}{ Average Age 2 of CT residents } & -0.0001 & $-0.0001 *$ & $0.0004 * * *$ \\
\hline & $(0.0001)$ & $(0.0001)$ & $(0.0001)$ \\
\hline \multirow[t]{2}{*}{ Share of CT who married } & $0.8277 * * *$ & $0.8526 * * *$ & $0.3008 * * *$ \\
\hline & $(0.0330)$ & $(0.0377)$ & $(0.0524)$ \\
\hline \multirow[t]{2}{*}{ Share of CT citizens } & $0.3555 * * *$ & $0.3036^{* * *}$ & $-0.5383 * * *$ \\
\hline & $(0.0730)$ & $(0.0833)$ & $(0.2016)$ \\
\hline \multirow[t]{2}{*}{$\mathrm{CT}$ is a $\mathrm{MSA}=0,1$} & $-0.1660 * * *$ & & \\
\hline & $(0.0057)$ & & \\
\hline \multirow[t]{2}{*}{ Constant } & $-2.693 * * *$ & $-3.028 * * *$ & -0.0444 \\
\hline & $(0.2531)$ & $(0.2792)$ & $(0.5465)$ \\
\hline Obs. (number of census tracts) & 64,083 & 50,414 & 13,669 \\
\hline R-squared & 0.9783 & 0.9779 & 0.9515 \\
\hline
\end{tabular}

Notes: Standard errors are in parentheses and clustered at the county level. 
Table B3. Political Activism

\begin{tabular}{|c|c|c|c|}
\hline Regressors: & $\begin{array}{c}\text { Full } \\
\text { sample }\end{array}$ & $\begin{array}{l}\text { MSA } \\
\text { only }\end{array}$ & $\begin{array}{c}\text { non-MSA } \\
\text { only }\end{array}$ \\
\hline \multirow[t]{2}{*}{ Recent In-Migration } & $-1.409 * * *$ & $-1.355 * * *$ & $-0.8066^{* * *}$ \\
\hline & $(0.1553)$ & $(0.1631)$ & $(0.1718)$ \\
\hline \multirow[t]{2}{*}{ Near Census SK level } & $1.323 * * *$ & $1.375 * * *$ & $0.7908 * * *$ \\
\hline & $(0.0603)$ & $(0.0643)$ & $(0.0406)$ \\
\hline \multirow[t]{2}{*}{ Amenities Scale } & $0.0139 * *$ & $0.0178 * *$ & -0.0016 \\
\hline & $(0.0063)$ & $(0.0082)$ & $(0.0016)$ \\
\hline \multirow[t]{2}{*}{ Share of CT HS only } & $0.7305 * * *$ & $0.7184 * * *$ & $0.6389 * * *$ \\
\hline & $(0.0709)$ & $(0.0766)$ & $(0.0490)$ \\
\hline \multirow[t]{2}{*}{ Share of CT SCOLL only } & $1.738 * * *$ & $1.660 * * *$ & $1.578 * * *$ \\
\hline & $(0.0756)$ & $(0.0787)$ & $(0.0821)$ \\
\hline \multirow[t]{2}{*}{ Share of CT COLL degree } & $2.396 * * *$ & $2.357 * * *$ & $2.321 * * *$ \\
\hline & $(0.0907)$ & $(0.0935)$ & $(0.0682)$ \\
\hline \multirow[t]{2}{*}{ Share of CT Hispanic } & $-0.1509 * * *$ & $-0.1318 * * *$ & $-0.2439 * * *$ \\
\hline & $(0.0433)$ & $(0.0492)$ & $(0.0297)$ \\
\hline \multirow[t]{2}{*}{ Share of CT black non-Hispanic } & $0.1739 * * *$ & $0.1789 * * *$ & $0.0856 * * *$ \\
\hline & $(0.0263)$ & $(0.0282)$ & $(0.0168)$ \\
\hline \multirow[t]{2}{*}{ Share of CT oth. race non-Hisp } & $-0.6634 * * *$ & $-0.6604 * * *$ & $-0.6179 * * *$ \\
\hline & $(0.0555)$ & $(0.0758)$ & $(0.0209)$ \\
\hline \multirow[t]{2}{*}{ Average Age of CT residents } & $-0.0191^{*}$ & -0.0156 & 0.0124 \\
\hline & $(0.0098)$ & $(0.0109)$ & $(0.0083)$ \\
\hline \multirow[t]{2}{*}{ Average Age2 of CT residents } & 0.0000 & 0.0000 & $-0.0002 * * *$ \\
\hline & $(0.0001)$ & $(0.0001)$ & $(0.0001)$ \\
\hline \multirow[t]{2}{*}{ Share of CT who married } & $-0.0800 *$ & $-0.0848^{*}$ & 0.0323 \\
\hline & $(0.0451)$ & $(0.0496)$ & $(0.0308)$ \\
\hline \multirow[t]{2}{*}{ Share of CT citizens } & $0.4362 * * *$ & $0.5073 * * *$ & $0.3648 * * *$ \\
\hline & $(0.0738)$ & $(0.0758)$ & $(0.1198)$ \\
\hline \multirow[t]{2}{*}{$\mathrm{CT}$ is a $\mathrm{MSA}=0,1$} & $0.0772 * * *$ & & \\
\hline & $(0.0070)$ & & \\
\hline \multirow[t]{2}{*}{ Constant } & -0.0268 & -0.0131 & $-1.572 * * *$ \\
\hline & $(0.3337)$ & $(0.3641)$ & $(0.3053)$ \\
\hline Obs. (number of census tracts) & 64,083 & 50,414 & 13,669 \\
\hline R-squared & 0.9275 & 0.9271 & 0.9644 \\
\hline
\end{tabular}

Notes: Standard errors are in parentheses and clustered at the county level. 
Table B4. Political Engagement

\begin{tabular}{|c|c|c|c|}
\hline Regressors: & $\begin{array}{c}\text { Full } \\
\text { sample }\end{array}$ & $\begin{array}{l}\text { MSA } \\
\text { only }\end{array}$ & $\begin{array}{c}\text { non-MSA } \\
\text { only }\end{array}$ \\
\hline \multirow[t]{2}{*}{ Recent In-Migration } & $-0.9420 * * *$ & $-0.9442 * * *$ & $-0.7117 * * *$ \\
\hline & $(0.0754)$ & $(0.0800)$ & $(0.1547)$ \\
\hline \multirow[t]{2}{*}{ Near Census SK level } & $0.6657 * * *$ & $0.6383 * * *$ & $0.9774 * * *$ \\
\hline & $(0.0362)$ & $(0.0367)$ & $(0.0449)$ \\
\hline \multirow[t]{2}{*}{ Amenities Scale } & 0.0025 & 0.0027 & $-0.0038 * * *$ \\
\hline & $(0.0026)$ & $(0.0033)$ & $(0.0014)$ \\
\hline \multirow[t]{2}{*}{ Share of CT HS only } & $1.323 * * *$ & $1.283 * * *$ & $1.345^{* * *}$ \\
\hline & $(0.0460)$ & $(0.0574)$ & $(0.0473)$ \\
\hline \multirow[t]{2}{*}{ Share of CT SCOLL only } & $2.056 * * *$ & $2.077 * * *$ & $1.908 * * *$ \\
\hline & $(0.0417)$ & $(0.0455)$ & $(0.0777)$ \\
\hline \multirow[t]{2}{*}{ Share of CT COLL degree } & $2.699 * * *$ & $2.689 * * *$ & $2.620 * * *$ \\
\hline & $(0.0439)$ & $(0.0502)$ & $(0.0627)$ \\
\hline \multirow[t]{2}{*}{ Share of CT Hispanic } & $-0.0786 * * *$ & $-0.0646 * *$ & $-0.2191 * * *$ \\
\hline & $(0.0273)$ & $(0.0319)$ & $(0.0381)$ \\
\hline \multirow[t]{2}{*}{ Share of CT black non-Hispanic } & $0.1699 * * *$ & $0.1757 * * *$ & $0.1175 * * *$ \\
\hline & $(0.0162)$ & $(0.0179)$ & $(0.0152)$ \\
\hline \multirow[t]{2}{*}{ Share of CT oth. race non-Hisp } & $-0.8610 * * *$ & $-0.8575 * * *$ & $-0.7892 * * *$ \\
\hline & $(0.0358)$ & $(0.0497)$ & $(0.0221)$ \\
\hline \multirow[t]{2}{*}{ Average Age of CT residents } & $0.1149 * * *$ & $0.1105^{* * *}$ & $0.1415 * * *$ \\
\hline & $(0.0059)$ & $(0.0064)$ & $(0.0088)$ \\
\hline \multirow[t]{2}{*}{ Average Age 2 of CT residents } & $-0.0006^{* * *}$ & $-0.0005 * * *$ & $-0.0008 * * *$ \\
\hline & $(0.0001)$ & $(0.0001)$ & $(0.0001)$ \\
\hline \multirow[t]{2}{*}{ Share of CT who married } & $0.4823 * * *$ & $0.4910^{* * *}$ & $0.5474 * * *$ \\
\hline & $(0.0311)$ & $(0.0341)$ & $(0.0360)$ \\
\hline \multirow[t]{2}{*}{ Share of CT citizens } & $1.373 * * *$ & $1.413 * * *$ & $0.9541 * * *$ \\
\hline & $(0.0633)$ & $(0.0707)$ & $(0.1512)$ \\
\hline \multirow[t]{2}{*}{$\mathrm{CT}$ is a $\mathrm{MSA}=0,1$} & $0.1864 * * *$ & & \\
\hline & $(0.0041)$ & & \\
\hline \multirow[t]{2}{*}{ Constant } & $-6.978 * * *$ & $-6.750 * * *$ & $-7.083 * * *$ \\
\hline & $(0.1634)$ & $(0.1818)$ & $(0.3177)$ \\
\hline Obs. (number of census tracts) & 64,083 & 50,414 & 13,669 \\
\hline R-squared & 0.9683 & 0.9694 & 0.9736 \\
\hline
\end{tabular}

Notes: Standard errors are in parentheses and clustered at the county level. 
Table B5. Community Involvement

\begin{tabular}{|c|c|c|c|}
\hline Regressors: & $\begin{array}{c}\text { Full } \\
\text { sample }\end{array}$ & $\begin{array}{l}\text { MSA } \\
\text { only }\end{array}$ & $\begin{array}{c}\text { non-MSA } \\
\text { only }\end{array}$ \\
\hline \multirow[t]{2}{*}{ Recent In-Migration } & $-1.043 * * *$ & $-0.9821 * * *$ & $-1.504 * * *$ \\
\hline & $(0.1100)$ & $(0.1157)$ & $(0.1945)$ \\
\hline \multirow[t]{2}{*}{ Near Census SK level } & $1.163 * * *$ & $1.169 * * *$ & $1.275^{* * *}$ \\
\hline & $(0.0697)$ & $(0.0756)$ & $(0.0512)$ \\
\hline \multirow[t]{2}{*}{ Amenities Scale } & $0.0130 * *$ & $0.0152 * *$ & $0.0043 * *$ \\
\hline & $(0.0053)$ & $(0.0067)$ & $(0.0019)$ \\
\hline \multirow[t]{2}{*}{ Share of CT HS only } & $0.4768 * * *$ & $0.4233 * * *$ & $0.8283 * * *$ \\
\hline & $(0.0455)$ & $(0.0520)$ & $(0.0616)$ \\
\hline \multirow[t]{2}{*}{ Share of CT SCOLL only } & $1.448 * * *$ & $1.337 * * *$ & $1.898 * * *$ \\
\hline & $(0.0489)$ & $(0.0504)$ & $(0.0905)$ \\
\hline \multirow[t]{2}{*}{ Share of CT COLL degree } & $2.170 * * *$ & $2.104 * * *$ & $2.699 * * *$ \\
\hline & $(0.0587)$ & $(0.0628)$ & $(0.0823)$ \\
\hline \multirow[t]{2}{*}{ Share of CT Hispanic } & 0.0194 & 0.0223 & $-0.2482 * * *$ \\
\hline & $(0.0393)$ & $(0.0436)$ & $(0.0386)$ \\
\hline \multirow[t]{2}{*}{ Share of CT black non-Hispanic } & $0.4133 * * *$ & $0.4226 * * *$ & $0.2421 * * *$ \\
\hline & $(0.0222)$ & $(0.0236)$ & $(0.0229)$ \\
\hline \multirow[t]{2}{*}{ Share of CT oth. race non-Hisp } & $-0.3885 * * *$ & $-0.4324 * * *$ & $-0.3340 * * *$ \\
\hline & $(0.0461)$ & $(0.0551)$ & $(0.0303)$ \\
\hline \multirow[t]{2}{*}{ Average Age of CT residents } & $0.0536 * * *$ & $0.0595 * * *$ & $0.0271 * *$ \\
\hline & $(0.0071)$ & $(0.0080)$ & $(0.0113)$ \\
\hline \multirow[t]{2}{*}{ Average Age2 of CT residents } & $-0.0006^{* * *}$ & $-0.0006^{* * *}$ & $-0.0003 * * *$ \\
\hline & $(0.0001)$ & $(0.0001)$ & $(0.0001)$ \\
\hline \multirow[t]{2}{*}{ Share of CT who married } & $0.5619 * * *$ & $0.5960 * * *$ & $0.2158 * * *$ \\
\hline & $(0.0316)$ & $(0.0339)$ & $(0.0461)$ \\
\hline \multirow[t]{2}{*}{ Share of CT citizens } & $0.7080 * * *$ & $0.7485 * * *$ & 0.0268 \\
\hline & $(0.0517)$ & $(0.0522)$ & $(0.1361)$ \\
\hline \multirow[t]{2}{*}{$\mathrm{CT}$ is a $\mathrm{MSA}=0,1$} & $0.0436 * * *$ & & \\
\hline & $(0.0049)$ & & \\
\hline \multirow[t]{2}{*}{ Constant } & $-3.012 * * *$ & $-3.124 * * *$ & $-1.571 * * *$ \\
\hline & $(0.2229)$ & $(0.2475)$ & $(0.3772)$ \\
\hline Obs. (number of census tracts) & 64,083 & 50,414 & 13,669 \\
\hline R-squared & 0.9183 & 0.9240 & 0.8661 \\
\hline
\end{tabular}

Notes: Standard errors are in parentheses and clustered at the county level. 
Table B6. Sociability

\begin{tabular}{|c|c|c|c|}
\hline Regressors: & $\begin{array}{c}\text { Full } \\
\text { sample }\end{array}$ & $\begin{array}{l}\text { MSA } \\
\text { only }\end{array}$ & $\begin{array}{c}\text { non-MSA } \\
\text { only }\end{array}$ \\
\hline \multirow[t]{2}{*}{ Recent In-Migration } & $-0.6861 * * *$ & $-0.6486^{* * *}$ & $-0.5903 * * *$ \\
\hline & $(0.1071)$ & $(0.1126)$ & $(0.2164)$ \\
\hline \multirow[t]{2}{*}{ Near Census SK level } & $1.102 * * *$ & $1.088 * * *$ & $1.376^{* * *}$ \\
\hline & $(0.0386)$ & $(0.0424)$ & $(0.0669)$ \\
\hline \multirow[t]{2}{*}{ Amenities Scale } & $0.0135 * * *$ & $0.0147 * * *$ & $0.0069 * * *$ \\
\hline & $(0.0028)$ & $(0.0037)$ & $(0.0015)$ \\
\hline \multirow[t]{2}{*}{ Share of CT HS only } & $0.5738 * * *$ & $0.5913 * * *$ & $0.4194 * * *$ \\
\hline & $(0.0371)$ & $(0.0409)$ & $(0.0557)$ \\
\hline \multirow[t]{2}{*}{ Share of CT SCOLL only } & $1.122 * * *$ & $1.097 * * *$ & $1.032 * * *$ \\
\hline & $(0.0450)$ & $(0.0465)$ & $(0.1040)$ \\
\hline \multirow[t]{2}{*}{ Share of CT COLL degree } & $1.257 * * *$ & $1.253 * * *$ & $1.112 * * *$ \\
\hline & $(0.0557)$ & $(0.0581)$ & $(0.0856)$ \\
\hline \multirow[t]{2}{*}{ Share of CT Hispanic } & $-0.4495 * * *$ & $-0.4500 * * *$ & $-0.4605 * * *$ \\
\hline & $(0.0315)$ & $(0.0353)$ & $(0.0373)$ \\
\hline \multirow[t]{2}{*}{ Share of CT black non-Hispanic } & $-0.6430 * * *$ & $-0.6433 * * *$ & $-0.6869 * * *$ \\
\hline & $(0.0192)$ & $(0.0208)$ & $(0.0171)$ \\
\hline \multirow[t]{2}{*}{ Share of CT oth. race non-Hisp } & $-0.7822 * * *$ & $-0.7750 * * *$ & $-0.8442 * * *$ \\
\hline & $(0.0267)$ & $(0.0330)$ & $(0.0217)$ \\
\hline \multirow[t]{2}{*}{ Average Age of CT residents } & $-0.1109 * * *$ & $-0.1095 * * *$ & $-0.1052 * * *$ \\
\hline & $(0.0072)$ & $(0.0080)$ & $(0.0106)$ \\
\hline \multirow[t]{2}{*}{ Average Age2 of CT residents } & $0.0008 * * *$ & $0.0008 * * *$ & $0.0007 * * *$ \\
\hline & $(0.0001)$ & $(0.0001)$ & $(0.0001)$ \\
\hline \multirow[t]{2}{*}{ Share of CT who married } & $-0.2030 * * *$ & $-0.2047 * * *$ & $-0.2004 * * *$ \\
\hline & $(0.0299)$ & $(0.0325)$ & $(0.0336)$ \\
\hline \multirow[t]{2}{*}{ Share of CT citizens } & $0.3082 * * *$ & $0.3326 * * *$ & $0.3294 * *$ \\
\hline & $(0.0601)$ & $(0.0617)$ & $(0.1426)$ \\
\hline \multirow[t]{2}{*}{$\mathrm{CT}$ is a $\mathrm{MSA}=0,1$} & $-0.2132 * * *$ & & \\
\hline & $(0.0043)$ & & \\
\hline \multirow[t]{2}{*}{ Constant } & $2.842 * * *$ & $2.555^{* * *}$ & $2.872 * * *$ \\
\hline & $(0.2168)$ & $(0.2378)$ & $(0.3820)$ \\
\hline Obs. (number of census tracts) & 64,083 & 50,414 & 13,669 \\
\hline R-squared & 0.9312 & 0.9295 & 0.9479 \\
\hline
\end{tabular}

Notes: Standard errors are in parentheses and clustered at the county level. 